\title{
ORDEN CORPORAL Y REPRESENTACIONES RACIALES, DE CLASE Y GÉNERO EN LA CIUDAD DE CUENCA (ECUADOR) 1
}

\author{
BODY ORDER AND RACIAL, CLAS AND GENDER REPRESENTATION \\ IN THE CITY OF CUENCA (ECUADOR)
}

\author{
José María Valcuende del Río ${ }^{1,2}$ y Piedad Vásquez Andrade 3
}

\begin{abstract}
El poder en las ciudades coloniales latinoamericanas ha sido representado como "blanco" y "masculino". Por medio de este texto nos aproximaremos a las transformaciones experimentadas en las representaciones raciales, de clase y género en la ciudad de Cuenca (Ecuador) a partir del análisis comparativo de la elección de las reinas y cholas cuencanas, en un contexto social marcado por la reivindicación del mestizaje cultural.
\end{abstract}

Palabras claves: raza, sexo, clase social, mestizaje, concursos de belleza, Cuenca, Ecuador.

\begin{abstract}
In Latin American colonial towns power has been represented as "white" and "male". In this work we approach the transformations in the racial, class and gender representations in the city of Cuenca (Ecuador). This is done through the comparative analysis of Cuenca Queens and "Cholas cuencanas" contests choice, in a social setting marked by the claim of cultural mix.
\end{abstract}

Key words: Race, class, body, cultural mix, beauty contests, Cuenca, Ecuador.

A partir de la articulación del género, raza, sexo y sexualidad, jerarquizamos los cuerpos: biológicos y culturales, productivos y reproductivos, públicos y privados (Llamas 1998) e hipercorporizamos los cuerpos subalternos, siempre feminizados y racializados. La raza, entendida como clasificación arbitraria de rasgos corporales a los que se les atribuyen formas de ser y de estar, ha sido y es un elemento más que inscribe posiciones de poder en los propios cuerpos. Un hecho de indudable centralidad en contextos de colonización. Los debates que se produjeron en la conquista de América en relación con la humanidad de los indígenas (Bestard y Contreras 1987) muestran una lectura prerracial que sirvió para justificar el proceso de dominación del mundo occidental, y los papeles que corresponden a conquistadores y conquistados (Quijano 2000). Pero la vinculación entre raza, género, nación y clase ha sido también central en la legitimación de las desigualdades que conformaron el Tercer Mundo (Escobar 2007).
Para Wade (2011:208) en el siglo XIX y parte del XX "Una 'raza' podía definirse no solo en términos de aspectos de la biología (...), también en términos de las características morales e intelectuales". Determinados discursos científicos daban carta de naturaleza al racismo social. Pero la raza como instrumento de dominación presenta similitudes notables con la traducción social del sexo (Stolcke 1992). Ambas están estrechamente imbricadas por varias razones: (1) la feminidad es una construcción creada por y para los varones, en función de un control que es fundamentalmente sexual (Mackinon 1987); (2) el control de los cuerpos de las mujeres en las sociedades coloniales ha sido central para asegurar uno de los principios ideológicos sobre los que se sustentaban: la pureza de sangre (Stolcke 2009); (3) la reivindicación de las mujeres como sujetos históricos significó la invisibilización de aquellas que no respondían al modelo occidental/blanco, como han denunciado los feminismos indígenas y afros (Carneiro 2005:25).

\footnotetext{
Universidad Pablo de Olavide, Sevilla, España. jmvalrio@upo.es

Universidad de Cuenca (Proyecto Prometeo), Cuenca, Ecuador.

Universidad de Cuenca, Ecuador. piedadva66@hotmail.com
}

Recibido: diciembre 2014. Aceptado: diciembre 2015.

http://dx.doi.org/10.4067/S0717-73562016005000008. Publicado en línea: 8-febrero-2016. 
A su vez, la imagen corporal del hombre ha definido la máxima posición de poder. La masculinidad dominante jerarquiza a los hombres en relación con las mujeres, y a estos entre sí. Están los hombres que responden a la imagen del poder (Kimmel 1997), y aquellos que, de una u otra forma, son "feminizados" (entre otras cosas en función de su clase social y raza). Las lecturas en torno al sexo, raza y clase social, en cuanto realidades naturalizadas (Stolcke 1992), han definido y definen posiciones sociocorporales a partir del habitus (Bourdieu 1991), que estaría en la base de lo que denominaremos como orden corporal.

Por orden corporal entendemos la clasificación (política), la visualización (estética) y la valoración (moral) de los cuerpos en un sistema social determinado, en función del género, la clase social y la raza. El orden corporal es político, en cuanto que legitima la corporización de posiciones jeraquizadas en el entramado social; estético, ya que "la belleza" es definida en un sistema de relaciones/ representaciones/percepciones que convierten "lo blanco" en deseable. Esto no significa que otros cuerpos no lo sean; la diferencia es que "lo blanco" no solo es bello, es también inviolable, y por tanto tiene connotaciones morales, negadas a los cuerpos subalternos. El orden corporal no solo sitúa a los individuos en el ámbito de lo social, también define los campos de actuación a partir de los cuales los cuerpos pueden o no visibilizarse siguiendo estrategias de dominación y resistencia.

En las páginas siguientes nos centraremos en el análisis de la elección de la Reina de Cuenca y de la Chola cuencana; acontecimientos que juegan un papel central en la reproducción del imaginario comunitario, en función de la raza, género y clase social. Por comunidad entendemos una representación ideal que, por un lado, nos unifica en función de compartir un territorio (físico y/o simbólico) frente a "los otros", pero por otro nos jerarquiza a nivel interno, a partir de la desigual capacidad de acceso a los referentes de poder (Valcuende 1998; Valcuende y Narotsky 2005), que se ponen de manifiesto también en la propia lectura de los cuerpos.

Para realizar esta investigación recurrimos a una metodología cualitativa. Realizamos entrevistas semiestructuradas a miembros de diversos grupos étnicos y a informantes privilegiados. Hemos recopilado testimonios de mujeres, declaraciones realizadas en medios de comunicación y análisis de grabaciones relativas a los concursos de belleza. Las entrevistas se han complementado con observación directa en diferentes ámbitos durante 2013 y 2014, y en el seguimiento de la elección de la Reina de Cuenca y Chola cuencana celebradas en 2014.

Partimos de la hipótesis de que el progresivo proceso de mestizaje que reivindica la sociedad local constituye un mecanismo de invisibilización y reproducción de desigualdades. Para Kingman (2002:1) el mestizaje es "una estrategia discursiva generada desde el Estado", pero también "ha tomado la forma de políticas y dispositivos destinados a la ‘civilización' y urbanización de la población”. Un hecho de especial importancia en los contextos urbanos andinos, donde a pesar de la marcada diferencia en el imaginario entre lo urbano/letrado y lo popular "en la vida cotidiana los límites que separaban lo popular de lo no popular, lo urbano de lo no urbano, lo escriturado de lo no escriturado, eran, muchas veces, difusos" (Kingman 2009:47), y por tanto, cabría añadir, peligrosos ${ }^{2}$. En lo que algunos autores consideran como modernidad periférica (Kingman 2003), la inclusión de los sectores subalternos requería de un nuevo discurso, como el mestizaje, a partir del que se producía un cierto reconocimiento de los grupos racializados, recreando a su vez las jerarquías sociales (como comprobaremos posteriormente a partir de la reivindicación de la Chola cuencana). Y es que tal y como señala Stolcke (2008), la noción de mestizaje supone, contrariamente a lo que se puede suponer desde el "sentido común", una reafirmación de las diferencias sociorraciales, en cuanto que parte de la supuesta existencia de categorías "puras" que son fusionadas en un nuevo orden, lo que inevitablemente se traduce en la reproducción de estructuras de dominación.

Siguiendo estos planteamientos entendemos los concursos de belleza como parte de estos dispositivos a partir de los que se visibilizan, ordenan, jerarquizan y "civilizan" los cuerpos subalternos (grupos racializados -leídos en clave femenina-y las mujeres). Para este texto ha sido fundamental el trabajo realizado por Mancero (2011 y 2013), que nos ha permitido contextualizar el papel de la Chola cuencana a nivel histórico. Nuestro aporte fundamental concerniente a estos trabajos es el análisis de estos eventos desde una perspectiva de género, en relación con la conformación de lo que hemos denominado "orden corporal", centrándonos en la significación de los concursos de belleza, desde una perspectiva comparativa. 


\section{Procesos de Identificación en la Ciudad de Cuenca}

Cuenca se representa fundamentalmente como una ciudad "mestiza". Lo mestizo forma parte de un imaginario en el que las clasificaciones étnicas y de género se subsumen con posiciones de clase y categorías raciales. Las familias blancas representaban la cúspide de una sociedad notoriamente jerarquizada. El blanco, que ha sido la imagen del poder, hace referencia a los descendientes de españoles, a los que se fueron sumando grupos procedentes de otros contextos, blanqueados en virtud de su posición económica. La capacidad económica blanquea, pero sutiles diferencias señalan posiciones desiguales entre la vieja y la nueva elite ${ }^{3}$. Dentro de la categoría "blanco" encontramos al denominado "chazo" o blanco rural. Este ocupaba una posición de poder superior a otros campesinos, pero inferior a los blancos urbanos. Entre la población blanca e indígena están los mestizos, jerarquizados entre los urbanos "blanqueados" y el mestizo rural. En esta categoría se encuentran los invisibilizados "cholos" y especialmente "las cholas", identificadas fundamentalmente por una forma de vestir y sus dos trenzas características, que las diferencian de las indígenas. Las cholas pueden ser urbanas o rurales; indígenas asimiladas a los mestizos, y mestizas que ocupan una posición inferior, en relación con los mestizos blanqueados. Y es que si hay un hecho que nos ayuda a entender las diferentes jerarquizaciones entre blancos, mestizos e indígenas, es precisamente la dualidad urbano/ campesino. Un mundo, este último, sospechoso por próximo al mundo de aquellos que están en la base de la pirámide social: los indios o runas. La expresión habitual pero cada vez menos utilizada en Cuenca de "indio atrevido" o "indio alzado"4 indica la imposibilidad de transgredir los límites definidos por un orden corporal, que niega la agencia a aquellos que están o mejor que son en función de los que ostentan el poder: "indio rabo verde", "medalla ha de tener", "indio mitayo verde"5. "Mitayo/a pata rajada". "Me salió el indio". "El indio lo que no hace a la entrada lo hace a la salida"...

La "urbanidad" y la "indianidad" indisociables vinculadas al origen y evolución de la ciudad, discursivamente se muestran como realidades incompatibles, de manera especial desde la mirada de los grupos dominantes, que se han reivindicado en función de su pasado colonial europeo y especialmente español. Cuenca es así la ciudad "culta", "Atenas del Ecuador", su arquitectura patrimonial ${ }^{6}$ se vincula a la herencia española y francesa $^{7}$, que se complementa y contrapone a la propia herencia indígena (cañari e inca), que dejó sus huellas arqueológicas visibilizadas en zonas urbanas como Pumapungo y Todos los Santos. En Cuenca lo indígena, a pesar de su contemporaneidad, es arqueología, en contraposición a la herencia europea que se convierte en Historia. La invasión española, mito de origen cuencano, marca un antes y un después a todos los niveles ${ }^{8}$, La Historia de la ciudad es fundamentalmente la de su elite, definida en clave "blanca" y masculina, como se evidencia en su himno, en el que se nombran los "grandes" apellidos cuencanos. Aquellos que en función de sus posiciones de género, clase, sexo y raza tuvieron la capacidad de representar "el patrio esplendor"
Malos, Vásquez, Arízagas, Vélez, áureas plumas, helenos cinceles tuyos, Cuenca, tus próceres son. De su gloria tu gloria dimana, digna madre de egregios campeones y de sabios y santos varones, luminares de patrio esplendor 9 .

Sin embargo, la incorporación del discurso de la interculturalidad ha supuesto un cambio en la autopercepción de los cuencanos y cuencanas. Para entender este proceso es necesario tener en cuenta las transformaciones experimentadas por la sociedad ecuatoriana. El primero, la reivindicación del mestizaje, potenciado por el Estado (Kingman 2002), que progresivamente se ha consolidado como discurso dominante. El segundo, la visibilización de los pueblos indígenas, que adquieren un protagonismo notable en la vida sociopolítica nacional a finales de los años ochenta y especialmente en la década de los noventa del siglo XX (Chiriboga 2004). Este proceso se ha traducido en una recreación de "lo indígena" que adquiere valor para las nuevas elites indígenas y otros sectores sociales para los que se ha convertido en un signo de distinción. Así, en algunas entrevistas realizadas en Cuenca a personas que, a priori, podrían ser consideradas como no indígenas, nos encontramos con afirmaciones como "todos los cuencanos somos indígenas" o "todos somos cañaris". Una reivindicación sentimental de "un ser" que lo es en tanto que dejó de serlo... Lo indígena, desde el contexto urbano, se entiende como 
irrecuperable e incompatible con la modernización. Esta reivindicación de un indígena "arqueologizado" ha fundamentado un discurso nacionalista y localista, que se contrapone al papel jugado por las antiguas elites blancas, legitimando así el acceso al poder de otros grupos tradicionalmente excluidos. La reivindicación del mestizaje hizo posible visibilizar a grupos minorizados, que no minoritarios. Asistimos así a un blanqueamiento de los que acceden al poder, un cierto oscurecimiento de los que mantuvieron posiciones sociales privilegiadas, y una exotización de los mestizos rurales e indígenas contemporáneos, así como a la invisibilización histórica de la minoría afro, aun no asumida como parte de la historia nacional y mucho menos de la cuencana.

No es extraño que parte de "los blancos" de clase media y alta que se definen como "progresistas", "de izquierdas", se asuman también como mestizos. "Lo mestizo-blanco" es hoy el lugar políticamente correcto donde están aquellos que aspiran a las esferas de poder y aquellos que pretenden encarnar "la normalidad". Sin embargo, la idea de mestizaje no ha significado, ni mucho menos, una sociedad “desracializada" (Rahier 1999).

\section{La Recreación de la Chola Cuencana}

El término chola no es exclusivo de Ecuador y se extiende a otros países latinoamericanos. Pero ahora no nos interesa analizar tanto el origen de este término ni su evolución histórica, como la recreación discursiva de la "Chola cuencana". Una representación reivindicada en monumentos, textos literarios, manifestaciones de carácter popular, desfiles, carteles turísticos y publicitarios, mercados populares de especial atractivo para visitantes, como "el de las flores", y cada vez más en las campañas de marketing que venden la imagen de la ciudad y de su importante producción artesanal...

En 1949 Rafael Carpio compone la canción "Chola Cuencana" (Correa 2008:85, 86), que se transformará en un auténtico himno local, a partir del romance de Ricardo Darquea ${ }^{10}$.

Chola cuencana, mi chola, /capullito de Amacay, /en ti cantan y en ti ríen/las aguas del Yanuncay//Eres España que canta/en Cuenca del Ecuador,/con reír de castañuelas/y llanto del rondador.//Con tu donaire y majeza/evocas Andalucía;/pero en todos tus sentires/florece la cuencanía//Hay en tu cara morena/frescura de amanecer;/y el sol quisiera en tus ojos/cada día atardecer (Composición Chola Cuencana).

Es en ese período cuando el Círculo Agrario Cantonal, que concentró a una parte de la elite, inicia los concursos de Chola cuencana (Mancero 2011). En 1957, a su vez, se inaugura el monumento a la Chola cuencana, encargado a un escultor español, situado en una zona periférica de la ciudad. Toda una serie de acontecimientos muestran cómo se produce un proceso de fijación de esta imagen en la década de los cincuenta, paradójicamente reivindicada por una parte de la elite local. Lo que para Mancero (2011) formaría parte de una estrategia de la elite por incorporar a los sectores subalternos, desde una posición de subsidiaridad, en la conformación de la identidad local.

No es casual que esta reivindicación identitaria sea realizada desde el punto de vista femenino. La imagen de la Chola cuencana, que no del cholo, supone un acto performativo a partir del que las cholas urbanas en forma progresiva se van ruralizando (independientemente de su presencia pasada y presente en la ciudad), y las mujeres rurales son reinventadas en base de una imagen patrimonializada y esencializada. La Chola cuencana de este modo pasa a definir a un grupo de mujeres, pero es un disfraz que se utiliza para representar "lo exótico" en contextos festivo-ceremoniales, desfiles escolares y cómo no, en la propia celebración del concurso de la Chola cuencana. Lo curioso de este fenómeno es que la exhibición de estos disfraces convive con las cholas campesinas y urbanas que observan cómo se reivindica identitariamente un papel que en la cotidianidad significa estigmatización ${ }^{11}$. La "reivindicación" de la chola es la "reivindicación" de una mujer mestiza fruto de la colonización (Eres la España que canta en Cuenca del Ecuador), que está al servicio de "los otros", no es por tanto simbólicamente una amenaza, como sí lo podría ser la imagen del cholo, en masculino, al contraponer discursivamente a aquellos que ocupan una posición de rivalidad en el orden corporal. La invisibilización del cholo es la negación de la masculinidad subalterna; una forma de feminización, en tanto que se niega a "los cholos" su capacidad de agencia, al mismo tiempo que reivindica la figura de sus mujeres. En este caso, la negación de lo masculino en los grupos subalternos es una doble reafirmación del poder de los hombres blancos en relación con 
los mestizos. Una reafirmación de género, de la masculinidad hegemónica, en cuanto que sitúa a los "verdaderos" hombres (los blancos) como los únicos cuerpos visibles en el ámbito político institucional, al mismo tiempo que exalta a las mujeres cholas en cuanto "objetos" de apropiación simbólica, lo que se traduce también en una reafirmación de clase sustentada en posiciones racializadas. Los cholos existen solo como disfraz pero no se reconocen ni discursivamente ni a nivel identitario; tampoco son visibles e identificables en la interacción cotidiana. Es cierto que la chola es también, fundamentalmente a nivel político, discurso y disfraz, pero sigue siendo visible en la cotidianidad de la realidad urbana y rural. Al igual que sucede en otros grupos subalternos como los indígenas, las mujeres son las encargadas de preservar la costumbre (por ejemplo mediante el mantenimiento de su ropa "tradicional" (Crain 2001; Tenori 2005).

\section{De Mujeres que Pueden ser Reinas, Princesas y Cholas}

Los trabajos realizados en relación con los cánones de belleza en el ámbito andino evidencian la reproducción estética de los modelos corporales dominantes. Es el caso de Bolivia, donde "las imágenes de la belleza física femenina son abrumadoramente blancas" (Canesa 2008:74), Perú (Valcuende y Cáceres 2014) o Ecuador (Moreno 2007; Muteba 2001; Rahier 1999).

Los concursos de belleza son contextos especialmente adecuados para analizar la representación y reproducción del ideal de belleza, pero también la disputa y los conflictos sociopolíticos (Pequeño 2004) generados en torno a la elección de un ideal de mujer que debe transformarse en emblema nacional o local (Muteba 2001). En Ecuador estos concursos han sido "dominados por concursantes blancas y mestizas" hasta 1996 (Moreno 2007:86), posteriormente asistimos a la inclusión ocasional de mujeres, en cierta medida blanqueadas, de rasgos afros. Las mujeres indígenas siguen al margen de la estética "nacional" (Moreno 2007:86). Sin embargo, se han ido generalizando concursos de belleza que visibilizan, desde lo local, otras corporalidades, también indígenas, en un proceso de hibridación, que asume la lógica global, al mismo tiempo que singulariza las diferencias étnicas (Pequeño 2007).

En Cuenca hay infinidad de concursos de belleza. Estos tienen un carácter didáctico y socializador. Las mujeres desde niñas aprenden el desigual valor de sus cuerpos, interiorizando el orden corporal que les corresponde en función de su género, raza y clase. Para las niñas encontramos concursos en las escuelas y colegios como princesitas de Navidad, reinas de Navidad, madrinas de curso, "señoritas deporte"12. Para adolescentes, el ya tradicional concurso de las morlaquitas (organizado por la Universidad Católica). Para las jóvenes, en función de su procedencia y clase social: reinas de los barrios (organizado por la Federación de barrios y Municipalidad de Cuenca), cholas de las parroquias y los dos actos emblemáticos de estos certámenes: la Reina de Cuenca y la Chola cuencana ${ }^{13}$.

El ideal de belleza en todos estos concursos ha estado marcado por el color blanco de piel, constituyendo el rubio (suco) un elemento de gran valor, alejado de la corporalidad de unas mujeres de entrada excluidas de los cánones de belleza (políticos, estéticos, morales).

¿Te has presentado alguna vez a algún concurso de este tipo?

No, las niñas no se presentaban, eran elegidas, y esta elección estaba condicionada por el color de la piel. Yo no podría ser elegida (mestiza, rasgos oscuros de piel, 29 años).

Desde niñas las mujeres interiorizan una posición de clase marcadamente racializada, en función de la edad y la procedencia social; concursos más o menos populares y, otros, como el de la Reina de Cuenca, vinculados históricamente con la elite local. Este certamen comienza en 1924, asociado a la que fuera la emblemática y elitista "Fiesta de Lira"14. Inicialmente la Reina era seleccionada entre las familias de "abolengo". Es el tiempo de las señoritas nobles, bellas, dignas y solteras. Así se presenta a "Su Majestad Yolanda I Reina de Cuenca":

Viene de una noble estirpe que ha prestigiado varias generaciones de la cuencanía. Ha llegado al trono con el esplendor de su belleza, con aureola de su virtud, con la claridad de su gracia. (...) Los ríos morlacos llevan su nombre. Yolanda, para pregonarlo en la inmensidad del mar por donde llegaron las tres carabelas (VV.AA 1957:30). 
Posteriormente cambia la forma de elección (votación pagada), aunque mantiene este carácter elitista. Los reinados podían tener una duración de varios años. Nos encontramos con coronas que se transmiten de madres a hijas e incluso a una nieta. Un esquema en el que las mujeres de alto estatus, blancas, representaban la belleza de la mujer cuencana.

En la década de 1980 sería un jurado el que elija a la candidata. Es un período de apertura del evento a otros grupos sociales. Actualmente las aspirantes necesariamente deben ser universitarias (una buena parte procede de universidades privadas), $\mathrm{y}$ aunque no es un requisito obligatorio se valora su conocimiento de inglés (aspecto, entre otros, que manifiesta la progresiva profesionalización del evento). Por supuesto, y esto no ha cambiado, deben ser solteras sin hijos. La evolución de la sociedad local ha posibilitado el acceso de mujeres de clase media y mestizas. Aunque la mujer mestiza que aspira al reinado debe emular los criterios estéticos y morales que definen "la urbanidad", prefiriéndose a la mestiza blanqueada. Para las mujeres rurales existen sus propios concursos, desarrollados en los ámbitos parroquiales, en el que se elige a las cholas de las parroquias, que luego competirán entre ellas por el codiciado reconocimiento de Chola cuencana. Su elección constituye uno de los actos centrales de las fiestas de Cuenca. Sus funciones son similares a las de la Reina, aunque su peso institucional es menor. Son múltiples los conflictos generados por la instrumentalización política de este evento, en los que no nos detendremos, y que ponen de manifiesto su potencial identitario ${ }^{15} \mathrm{y}$ la progresiva importancia de una imagen por la que han pugnado diversas instituciones ${ }^{16}$. Sí nos interesa detenernos en la regulación de este evento a partir de 2003, en el que se crea una ordenanza cantonal ${ }^{17}$. En dicha ordenanza se evidencia su progresiva ruralización, y el carácter de un acto que pretende "valorar y visibilizar el aporte de la mujer campesina al desarrollo local".

Para Mancero (2013) "lo rural" se convierte en un referente de la autenticidad. Lo campesino es aceptado en cuanto espacio y tiempo mítico, que niega la contemporaneidad y la urbanidad de las clases subalternas ${ }^{18}$ : "La Chola cuencana será auténtica en sus características etnoculturales y deberá utilizar su traje típico en los actos oficiales". Una autenticidad que pasa por su reconocimiento no solo en el ámbito de la política, también en el del mercado: "un hecho social que debe ser resaltado en el campo de la cultura y el turismo".

Sin embargo, por mucho que la ordenanza incida en "la autenticidad", la gente diferencia entre cholas "auténticas" y "disfrazadas". En una de las entrevistas realizadas a una de las cholas de las parroquias que se presentaba a Chola cuencana en 2014, que no viste habitualmente como chola, nos comentaba que independientemente de no vestirse como chola se sentía así. La marca que define a las cholas ya no es impuesta, especialmente para un grupo de mujeres que pueden manifestar su identidad rural en contextos festivo-ceremoniales y que pueden pasar por mujeres urbanas en otros contextos. Es decir, nos encontramos con las cholas que pueden elegir cómo y cuándo visualizarse (las que se visten para la ocasión), y aquellas para las que ser cholas no es una opción.

\section{La Elección de la Reina de Cuenca y Chola Cuencana en 2014}

La elección de la Reina de Cuenca se realizó en uno de los templos de la modernidad, los centros comerciales, en este caso, el Mall del Río; la de la Chola cuencana se desarrolló en un ámbito eminentemente popular: el parque Miraflores; el primer acto exigía una cierta etiqueta y pagar 20 dólares, el segundo es gratuito y de carácter masivo (con una presencia significativa de sectores populares urbanos y rurales). Los presentadores de las candidatas a Reina resaltaban sus aspectos biográficos: nivel de estudios, idiomas, aficiones, experiencia en labores sociales...; en el caso de las cholas no importaba su biografía. Las candidatas a reinas vestían sus lujosos trajes de diseñadores; las cholas lucían el "verdadero" traje de chola. La música en el acto de la Reina tenía un carácter internacional; en el de la Chola cuencana, la música tenía un carácter "étnico" y la conocida canción "Chola cuencana" acompañó todo el evento. En las reinas juegan un papel importante las empresas, fundamentalmente municipales, así como empresas de estilismo y moda; en el caso de las cholas, sus parroquias rurales. Las futuras reinas que aspiran a representar a la juventud urbana compiten individualmente, no se deben a su comunidad. En el caso de las cholas, sus escenificaciones y bailes inciden en una representación colectiva, por lo que en algún momento de la presentación son acompañadas por hombres, mujeres y niños 
de sus parroquias, que nos muestran un mundo rural bucólico y romántico.

Bailes que escenifican la elaboración de ladrillos, ordeñar una vaca, trasquilar a un borrego, la elaboración de la hoja toquilla o de la totora, la pampamesa, la minga, la pesca de la trucha, la celebración de fiestas patronales y religiosas... marcan el largo acto de elección de la Chola entre las 21 candidatas. La Chola cuencana ante todo es una imagen comunitaria, y como tal debe representar los aspectos más emblemáticos de su parroquia. Mientras "las barras" que animan a las candidatas a reinas aclaman sus nombres, en el caso de las cholas corean fundamentalmente a cada parroquia. Autenticidad versus pluralidad, tradición versus modernidad, comunitarismo versus individualismo, urbanidad versus ruralidad... son algunos elementos que sintetizan las características contrapuestas de estos dos acontecimientos.

Las preguntas que se realizan a las candaditas a Reina durante el evento van encaminadas a dilucidar quién de estas mujeres puede representar un auténtico modelo social (político, estético y moral). Preguntas relacionadas con "el problema" de la juventud, los efectos del cambio climático, el problema de la migración o con los aspectos necesarios para mejorar la vida de la ciudad, y por supuesto con temas vinculados con la familia o la asistencia social... En las respuestas encontramos algunos tópicos reiterativos que nos permiten entender la lógica del sentido común que define el ideal de feminidad cuencana: mujeres preparadas, con un cierto nivel de formación, pero sobre todo mujeres con "valores" familiares y religiosos, capaces de enfrentar, desde la representación femenina del orden corporal, el manido deterioro social:

(...) Me encantaría generar espacios de actividades recreativas, con la familia y la comunidad, para fomentar la inclusión". Es preciso recuperar "los principios de la familia que se han ido perdiendo". "Aprendí que no existen distancias entre hombres y mujeres cuando se mira con esperanza un mismo objetivo, con confianza en Dios y siempre cuidando a la familia (respuestas de candidatas a Reina de Cuenca).

Un tópico recurrente en las preguntas tiene que ver con la experiencia de las candidatas en los trabajos con niños, niñas, jóvenes y adolescentes. Las referencias a las "futuras" generaciones es una constante, como lo es a los sectores excluidos: diversidad funcional, personas en prisión, pobreza, marginación social, ancianos... El carácter asistencial de esta figura constituye un aspecto clave que el jurado tendrá en cuenta para evaluar su "sensibilidad" y su capacidad para la realización de obras sociales durante el reinado. Una sensibilidad que debe enraizar con otro de los tópicos más mencionados: la tradición y el arraigo a una ciudad de la que se sienten orgullosas de pertenecer y representar. Una tradición vinculada con uno de los elementos identitarios más significativos de la ciudad: la religiosidad de la que hacen gala muchas de las candidatas. Amor, solidaridad, amistad, servicio, responsabilidad..., son algunos de los lugares comunes "programáticos" para la futura representante de las mujeres, urbanas, jóvenes, de clase media/media alta.

En relación con las cholas, las preguntas realizadas en la elección de 2014 comparten temáticas con las realizadas a las reinas, aunque en este caso hay una mayor incidencia en aspectos locales y "tradicionales" relativos al mundo rural, al que ellas van a representar (ver anexo).

Parece difícil imaginar a una candidata a Reina realizando alguna de las escenificaciones de las cholas cuencanas como trasquilar un borrego u ordeñar una vaca; igualmente sería extraño exigir el inglés a una candidata a Chola, sin poner en riesgo la ficción de la autenticidad. Y es que la elección de la Reina de Cuenca y la Chola cuencana marcan una clara jerarquía entre las mujeres del mundo rural y urbano. Esto se manifiesta en las características de las candidatas y del propio evento, en el tipo de regalos ${ }^{19}$, en los niveles de profesionalización, en las escenificaciones $\mathrm{y}$ en los diferentes papeles institucionales, que analizaremos a continuación.

\section{El Papel Sociopolítico de la Reina de Cuenca y la Chola Cuencana}

La Reina de Cuenca, durante un año, trabajará para la municipalidad (con un sueldo) realizando labores sociales y de representación institucional, integrándose en la Organización Acción Social, que tenía entre sus misiones: atender los servicios asistenciales, tales como: Comedores Municipales, Albergues, Guarderías, Asilos, Colonias Vacacionales, 
y otros similares que propenden al bienestar de la colectividad del Cantón Cuenca (Ordenanza para la creación de Acción Social Municipal, publicada el 21/07/86).

Acción Social se transforma en Fundación en 2008. La fundación es presidida por "el cónyuge o delegado del Alcalde del Cantón Cuenca, quien lo presidirá". Entre sus integrantes está una representante de la Fundación Reinas de Cuenca (en la que se integran todas las exreinas) y la Chola cuencana (lo que evidencia su progresiva institucionalización, de hecho en los estatutos de 1986 no se reconocía su presencia).

Las figuras públicas femeninas (Reina de Cuenca, Chola cuencana y esposa del alcalde) trabajan conjuntamente realizando labores asistenciales, conformando una feminidad que se construye y legitima a partir de la centralidad política de los concursos de belleza. La Reina de Cuenca y Chola cuencana representan la bella imagen del cuidado, entre sus funciones: reparto de caramelos a niños pobres, presencia en actos galantes con fines caritativos, recaudación de fondos con fines sociales, etc.

Como vemos los valores de la feminidad transcienden, en ciertos aspectos, las posiciones de clase. Tanto la Reina como la Chola son garantes de valores asociados con lo asistencial. Sin embargo el peso de "lo colectivo" y por tanto las diferencias entre mujeres con nombres y apellidos llamadas a ocupar posiciones relevantes en el entramado social y aquellas que están en el acto en función de representar una comunidad, marcan significativas diferencias de clase ${ }^{20}$. En ambos casos su posición pública es una prolongación del ámbito familiar y "privado", reforzando la visión de un poder que se sigue declinando de manera eminentemente masculina y heteronormativa. Un poder que reproduce las diferencias de un mundo urbano/blanco-mestizo y un mundo rural/indígenamestizo, que es integrado en la urbanidad, de forma subsidiaria, a partir de mecanismos civilizatorios que integran (y excluyen) a las mujeres y grupos racializados, en función de una lógica dominante, que recrea una belleza moral no muy diferente de los primeros concursos de Reina de Cuenca. Esto no es óbice para que estos concursos sean vistos por algunas mujeres como una forma bien de ascenso social, bien como una forma de reconocimiento en el caso de los sectores subalternos ${ }^{21}$.

\section{Conclusiones}

La elección de Reina ha tenido un claro componente de clase y racial, aunque se ha ido produciendo una incorporación de las mujeres de clase media, que emulan los comportamientos de la antigua elite. En el caso de la Chola cuencana asistimos a un concurso que pone en valor a las mestizas rurales, visibilizándolas en el ámbito urbano, desde la recreación de un mundo bucólico y comunitario. Un proceso no exento de contradicciones, ya que al mismo tiempo que se reivindica una imagen blanqueada e idealizada de la ruralidad, en la cotidianidad se manifiesta un cierto menosprecio por las cholas (tanto rurales como urbanas) y por supuesto por las indígenas que no aparecen como tales en los concursos de belleza de la ciudad de Cuenca o de las mujeres afros, en la práctica ausentes de los concursos locales.

Esta jerarquía de clase y racial se corresponde también con una jerarquía de género que se representa simbólicamente a partir de las funciones asignadas a las mujeres, vinculadas al mundo público a partir de tareas asociadas al ámbito privado. Los modelos de feminidad dominantes se reproducen en los concursos de Chola y en los de Reina, con algunos matices a partir de los que se marcan las diferencias entre la mujer urbana (individualizada, moderna, preparada) y la mujer campesina (colectiva, tradicional, trabajadora).

Sin embargo, hay cambios significativos relacionados con la progresiva institucionalización de la Chola y con el carácter menos elitista de la Reina, lo que pondría de manifiesto el proceso de urbanización de una mujer rural, que se hace visible especialmente en momentos festivo-ceremoniales y políticos. Pero esta imagen se presenta cada vez más como una opción para una parte de las mujeres rurales que les permite visibilizarse de forma contextual, en función de sus intereses y también de los de sus parroquias, a las que representa en el mundo urbano. En ese sentido podemos considerar a los concursos de belleza como parte de los dispositivos "civilizatorios" que han contribuido a recrear un discurso comunitario, que integra a determinados sectores en función de la lógica dominante del "mestizaje", reproduciendo la visión subalterna y feminizada de los grupos racializados, y de las propias mujeres, que continúan siendo un campo de batalla para la reafirmación del poder masculino. 
Agradecimientos: A la Secretaría de Educación Superior, Ciencia, Tecnología e Innovación de la República del Ecuador (SENECYT), a la DIUC de la U. de Cuenca y al Ministerio de Economía y Competitividad del Gobierno de España a los que agradecemos su patrocinio. A la Fundación Reinas de Cuenca que nos proporcionó diversas informaciones. A María José Machado que nos ayudó en el trabajo de campo y nos aportó una valiosa mirada. A María Marco y Pedro Cantero que nos apoyaron con sus comentarios. A los evaluadores de Chungara, que con sus sugerencias, críticas y recomendaciones contribuyeron de forma fundamental a mejorar este texto. Y especialmente a las mujeres que nos proporcionaron los testimonios que fueron tejiendo este texto.

\section{Referencias Citadas}

Bestard, J. y J. Contreras 1987. Bárbaros, Paganos, Salvajes y Primitivos. Barcanova, Barcelona.

Borrero, A.L. 2006. Cambios históricos en el paisaje de Cuenca, siglos XIX-XX. Procesos: Revista Ecuatoriana de Historia. 24:107-134.

Bourdieu, P. 1991. El Sentido Práctico. Taurus, Madrid.

Canessa, A. 2008. El sexo y el ciudadano: barbies y reinas de belleza en la era de Evo Morales. Raza, Etnicidad y Sexualidades: Ciudadanía y Multiculturalismo en América Latina, editado por P. Wade, F. Urrea Giraldo y M. Viveros Vigoya, pp. 69-105. Universidad Nacional de Colombia, Bogotá.

Carneiro, S. 2005. Ennegrecer al feminismo. La situación de la mujer negra en América Latina desde una perspectiva de género. Nouvelles Questions Féministes. Feminismos disidentes en América Latina y el Caribe, pp. 21-27.

Chiriboga, M. 2004. Desigualdad, exclusión étnica y participación política: el caso de la Conaie y Pachacutik en Ecuador. Alteridades 14:51-64.

Correa, F.J. 2009. Cofre Musical: Más de 300 Joyas del Pentagrama Inmortal. UEES, Universidad Espíritu Santo, Espíritu Santo.

Crain, M. 2001. La interpenetración de género y etnicidad: nuevas autorepresentaciones de la mujer indígena en el contexto urbano de Quito. En Antología Género, editado por G. Herrera M., pp. 353-381. FLACSO-Sede Ecuador/Junta de Andalucía, Quito.

Encalada, O. 2011. Regionalismo, Lengua y Contrastes. Corporación Editora Nacional, Quito.

Escobar, A. 2007. La Invención del Tercer Mundo: Construcción y Deconstrucción del Desarrollo. Norma, Caracas.

Kimmel, M. 1997. Homofobia, temor, vergüenza y silencio en la identidad masculina. Masculinidad/es, Poder y Crisis, editado por T. Valdés y J. Olavarría, pp. 49-63. Ediciones de las Mujeres, Santiago.

Kingman, E. 2002. Identidad, mestizaje e hibridación: sus usos ambiguos. Proposiciones 34. Santiago. http://www.flacso.org. ec/docs/artidenymestizaje.pdf

Kingman, E. 2003. Discursos y Relaciones de Poder en la Primera Mitad del Siglo XX. Rovira i Virgili, Tarragona.

Kingman, E. 2009. Cultura popular, vida cotidiana y modernidad periférica. Quaderns de l'Institut Català d'Antropologia 25:47-69.

Limón, A. 1999. ¿Patrimonio de quién? En Patrimonio Etnológico. Nuevas Perspectivas de Estudio, coordinado por E. Aguilar
Criado, pp. 8-15. Junta de Andalucía, Instituto Andaluz del Patrimonio Histórico, Granada.

Llamas, R. 1998. Teoría Torcida. Prejuicios y Discursos en Torno a la "Homosexualidad". Ed. Siglo XXI, Madrid.

MacKinnon, C. 1987. Sexuality. En Toward a Feminist Theory of the State, editado por C. MacKinnon, pp. 126-154. University Press, Harvard.

Mancero, M. 2011. Nobles y Cholos: La Disputa sobre un Proyecto Hegemónico Regional. Cuenca 1995-2005. Tesis de doctorado en Ciencias Sociales con mención en Estudios Políticos, FLACSO, Quito.

Mancero, M. 2013. Nobles y Cholos: Raza, Género y Clase en Cuenca. 1995-2005. FLACSO, Quito.

Moreno, M. 2007. Misses y concursos de belleza indígena en la construcción de la nación ecuatoriana. Iconos. Revista de Ciencias Sociales 28:81-91.

Muteba, J. 2001. Blanqueamiento en Esmeraldas: señoras, mujeres y concursos de belleza. En Diversidad ¿Sinónimo de Discriminación?, coordinado por P. Benalcázar y M.J. Salgado, pp. 219-241. Serie Investigación 4. Fundación Regional de Asesoría en Derechos Humanos (INREDH), Quito.

Pequeño, A. 2004. Historias de misses, historia de naciones. Iconos. Revista de Ciencias Sociales 20:114-117.

Pequeño, A. 2007. Las reinas. Los cuerpos comunitarios (Cap. III). En Imágenes en Disputa. Representaciones de Mujeres Indígenas Ecuatorianas. Tesis de Maestría en Ciencias Sociales, mención Género y Desarrollo. FLACSO, Quito.

Quijano, A. 2000. Colonialidad del poder, eurocentrismo y América Latina. En La Colonialidad del Saber: Eurocentrismo y Ciencias Sociales. Perspectivas Latinoamericanas, compilado por E. Lander, pp. 201-246. CLACSO, Consejo Latinoamericano de Ciencias Sociales, Buenos Aires.

Rahier, J.M. 1999. Mami, ¿qué será lo que quiere el negro? Representaciones racistas en la revista Vistazo, 1957-1991. En Ecuador racista: Imágenes e identidades, editado por E. Cervone y F. Rivera, pp. 73-109. FLACSO, Quito.

Stolcke, V. 1992. ¿Es el sexo para el género como la raza para la etnicidad? Mientras Tanto 48:87-112.

Stolcke, V. 2009. Los mestizos no nacen sino que se hacen. Avá, n.14http://www.scielo.org.ar/pdf/ava/n14/n14a02.pdf

Valcuende, J.M. 1998. Fronteras, Territorios e Identificaciones Colectivas. Blas Infante, Sevilla. 
Valcuende, J.M. y S. Narotsky 2005. Políticas de la memoria en los sistemas democráticos. X Congreso de Antropología de la FAAEE (Federación de Asociaciones de Antropología del Estado Español), Poder, Cultura y Mercado, coordinado por J.M. Valcuende y S. Narotzky, pp. 9-35. Sevilla.

Valcuende, J. M. y R. Cáceres 2014. Bricheros: sexo, raza y etnicidad en contextos turísticos. Revista de Estudios Sociales 49:72-86.
VV.AA. 1957. El Libro de Oro. Edición Conmemorativa del IV Centenario de la Fundación Española de Cuenca del Ecuador. El Tiempo, Cuenca.

VV.AA. 2012. San Roque: Indígenas Urbanos, Seguridad y Patrimonio. Coodinador Eduardo Kingman. FLACSO y EIFER, Quito.

Wade, P. 2011. Raza y naturaleza humana. Tabula Rasa 14: 205-226.

\section{Notas}

1 Este artículo forma parte del trabajo de investigación "Minorías étnicas y socioecosistemas urbanos"(SENESCYT), desarrollado en colaboración con la DIUC, que ha financiado el equipo de investigación del Aula de Derechos Humanos, integrado por Nilsson Araujo, Ángel Rodrigo Japón, Daisy Ayala, Fredy Javier Landy, Bolívar Ávila, Nataly Cajamarca y Alberto Chaves, que pueden considerarse coautores de este texto. La línea de investigación se enmarca en las del Proyecto LIESS (FEM2011-27295). Ministerio de Economía y Competitividad (Gobierno de España).

2 Efectivamente, esto se pone especialmente de manifiesto en ámbitos en los que son habituales los procesos de interacción entre grupos racializados diversos, como así ha sucedido por ejemplo en los mercados, que podemos considerar como auténticos "puentes" que vinculan lo rural y lo urbano. La centralidad de los mercados en las ciudades andinas ha sido analizada por diversos autores. Para el caso de Quito ver VVAA (2012), en Cuenca ver Mancero (2013).

3 Árboles genealógicos y narraciones de abuelos que conservaban en los baúles las capas, blasones y títulos de las casas nobles españolas, entre las que destacan las familias próceres de la independencia, forman parte del imaginario de la "verdadera" elite, que se contrapone a otras familias también blancas, a pesar de, por ejemplo, su pasado turco. Los testimonios recogidos señalan cómo la blanquitud definió espacios exclusivos como el acceso a determinados colegios en el que los rasgos fenotípicos y la posición de clase fueron y en algunos casos siguen siendo fundamentales para la admisión de los niños. Esto se percibe actualmente con los grupos de inmigrantes que han conseguido una cierta posición económica pero no acaban de ser aceptados en determinados círculos. Así respondían a un pregunta planteada por una de los integrantes de nuestro equipo: "Dice que tiene mucho dinero pero ¿y la cara qué?".

4 Expresión utilizada en todo Ecuador tal y como señala Encalada (2011), que analiza diferentes categorías que permiten entender la complejidad de denominaciones vinculadas a la clase social y a la raza.

5 Expresiones que hacen referencia a la marca mongólica asociada con mestizos e indígenas. Su presencia en los niños definía ya una posición social inscrita en los cuerpos.

$6 \quad$ El patrimonio es siempre una selección de elementos identitarios vinculados habitualmente con los grupos de poder (Limón 1999).

7 Para una aproximación a la transformación urbana de la ciudad ver Borrero (2006).

8 El día de la independencia y la fundación española de la ciudad son los actos centrales del calendario festivo local oficial, no hay ninguna conmemoración que celebre su pasado cañari/inca.

9 En 1939 se proclama oficialmente el himno de Cuenca, aunque la composición del poeta Luis Cordero Crespo es de principios del siglo XX. El texto de la declaración puede encontrarse en Avance No 246 http://www.revistavance. com/varios-mayo-2012/el-himno-de-cuenca-una-historiade-mas-de-cien-anos.html. Fecha de consulta: 11/12/2014.

10 No es habitual que se cante todo el poema. Son las dos primeras estrofas las que constituyen un auténtico himno popular.

11 En el uso cotidiano "Acholado" sirve para definir a una persona tímida, callada, sumisa, cobarde... "Acholar" significa hacer de menos, despreciar. Cuando alguna acción o acto recibe el calificativo de ser "cholo" equivale a ordinario.

12 Algunas informantes recuerdan que en el pasado en algunos colegios se pagaba para la elección de la princesita, reproduciéndose el mismo esquema que caracterizó la elección de la Reina. En 2012 el Ministerio de Educación acuerda: "Art. 7 PROHIBIR en los establecimientos educativos, públicos, fiscomisionales y particulares del sistema educativo nacional, la elección de reinas de belleza, princesitas de Navidad, madrinas y otros títulos que exalten las características físicas de las personas" (Registro Oficial $\mathrm{N}^{\mathrm{o}} 77$ ). A pesar de la prohibición algunos de estos concursos se siguen realizando.

13 En los últimos años se ha creado el Concurso de la Reina de Cuenca LGTBI. Denominación que dio lugar a un conflicto por cuanto que podía dar lugar a confusión con el de la Reina de Cuenca. Polémica significativa, como significativo es también la recurrencia a este tipo de concursos por parte de los grupos que pretenden ser reconocidos en el orden corporal, siguiendo ciertas regularidades con los concursos tradicionales, como la realización de actividades asistenciales.

14 Para una pormenorizada descripción histórica de este evento ver Diario el Mercurio. Reina de Cuenca: belleza y espiritualidad. Publicado el 11/03/2013. http://www.eltiempo. com.ec/noticias-cuenca/132023-reinas-de-cuenca-bellezay-espiritualidad/. Última consulta 15/12/2014.

15 Esta centralidad identatitaria se pone de manifiesto en la reproducción de estos concursos en los países de migración como Estados Unidos.

16 Mancero (2011) analiza los conflictos entre las diversas instituciones que pugnan por el evento. En el 2014 asistimos también a un nuevo conflicto, en este caso, entre la Prefectura, que jugó un papel realmente protagonista y la Municipalidad, lo que evidencia la rentabilidad del evento en términos políticos. 
17 El 17/10/2003 se publica la Ordenanza para la elección y gestión de la chola cuencana. http://www.cuenca.gov.ec/?q=node/8890 (última fecha de consulta 15/12/2014). En 2006 se reforma la ordenanza, con el fin de evitar los conflictos generados en elecciones anteriores, siendo encargada de la organización, la Asociación de Parroquias Rurales de Cuenca. Reforma y codificación de la Ordenanza que norma la elección de la Chola cuencana", fecha de publicación: 30/08/2006 www. cuenca.gov.ec/?q=system/files/229_ORDENANZA\%20229. doc (fecha de consulta 15/12/2014). En dicha ordenanza se anuncia la creación de la Fundación Chola Cuencana, aun no implementada.

18 Para Rahier (1999), en el proyecto nacional de mestizaje, que se inicia en el período republicano, "lo rural" era el ámbito de la barbarie en contraposición al mundo urbano blanco y blanco-mestizo. Un espacio por civilizar.
19 Uno de los que fuera regalos tradicionales de las cholas eran las máquinas de coser Singer. En los últimos años reciben una pequeña cantidad económica.

20 Los reinados son habitualmente una plataforma para la posterior ocupación de cargos públicos, de nominación o elección popular Algunas de las exreinas estudian comunicación e inician una carrera como presentadoras, reporteras, relaciones públicas, etc.

21 En algunas entrevistas realizadas las candidatas a cholas cuencanas reivindican la importancia de estos concursos como forma de reconocimiento de unas mujeres denostadas en el pasado. Los concursos para ellas contribuyen a visibilizar el papel de las mujeres en la ciudad, y a reivindicar una tradición que ha pasado a ser integrada en el discurso político local.

\begin{abstract}
ANEXO
¿Cómo debería integrarse a los jóvenes en la lucha contra la corrupción?/¿Concepción del Sumak Kausay?/¿Cuáles son los rasgos culturales característicos de la parroquia?/¿Cómo trabajaría para vincular el trabajo estatal con la producción artesanal de la parroquia?/¿Cuáles son las características de la chola cuencana?/¿Qué acciones propondría para contrarrestar los efectos negativos de la migración?/¿Opinión con respecto a la declaración de Cuenca como patrimonio de la humanidad por parte de la UNESCO?/ ¿Opinión con respecto a los Valores humanos en decadencia?/ ¿Qué acciones propondría para contrarrestar la extinción de la flora y la fauna?/ ¿Qué acciones propondría para promocionar la imagen de la parroquia?/ ¿Cómo deberían trabajar las autoridades para mejorar la

educación en el sector rural?/ ¿Cómo fomentaría usted el turismo comunitario?/ ¿Por qué es importante la planificación territorial rural? / ¿Qué concepto tiene sobre el papa Francisco? ¿LLas redes sociales como el Facebook, YouTube, entre otros, a su criterio, fomentan la educación en las personas o no es así? / El calentamiento global es evidente en estos momentos ¿Qué debería hacer la humanidad y los gobiernos para detener este proceso? / ¿Cómo trabajarían los GAD parroquiales en beneficio de las comunidades? / Recientemente se aprobó la ordenanza para sancionar a quienes consuman licor en los espacios públicos ¿Qué opina al respecto?

Preguntas concurso de Chola cuencana, 2014. Información recopilada por Fredy Javier Landy Hurtado.
\end{abstract}


